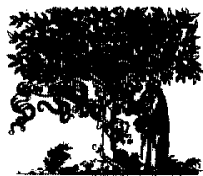

ELSEVIER

\title{
Pinacol rearrangement over metal-substituted aluminophosphate molecular sieves
}

\author{
Bo-Ya Hsu, Soofin Cheng * \\ Department of Chemistry, National Taiwan University. Taipei, Taiwan 106
}

\begin{abstract}
Pinacol rearrangement was found to proceed at relatively mild temperature over metal-substituted aluminophosphate molecular sieves. Pinacolone and 2,3-dimethyl-1,4-butadiene were the two main products obtained. The conversion of pinacol and the selectivities of these two products were found to be influenced by the metal species, the metal content, the crystalline structure of aluminophosphate and the solvent used in the liquid-phase reaction. Among the first row transition metal elements substituted in the AFI crystal structure, late transition metals seem to give better catalytic activities than the early ones. $\mathrm{Fe}^{3+}, \mathrm{Cu}^{2+}$ and $\mathrm{Ni}^{2+}$ in order are the three which give the highest pinacol conversions and pinacolone selectivities. The catalytic activity was found to have no direct correlation with the acid strength or amount of the acid sites on the catalysts. A mechanism involving the redox ability of Fe(III) and its stabilization of the carbenium ion intermediates was proposed. Besides, in comparison of the catalytic activities of Fe-substituted molecular sieves of different crystalline structures, the activity decreased in the order of APO-5 $>$ APO-11 $\geq$ APO-8 $>$ VPI-5 $>$ silicalite- 1 . Since the catalytic activity was independent of pore diameter, the liquid-phase reaction was considered to proced mainly on the outer surfaces of the catalysts. The hydrophilicity of the aluminophosphate surface was in favor of catalyzing the pinacol reaction, which involves polar reactants and less polar products. Moreover, high pinacol conversion was achieved by using solvents of low polarity. (C) 1998 Elsevier Science B.V. All rights reserved.
\end{abstract}

Key'words: Pinacol rearrangement; Aluminophosphate molecular sieve; Catalyst; Metal substitution; Solvent effect

\section{Introduction}

The discovery of a series of microporous aluminophosphates by Wilson and coworkers $[1,2]$ in 1982 opened up the new possibility of designing new materials for sorption and catalysis. By varying the templates and the synthesis conditions, aluminophosphates of profoundly different porous structures have been prepared. The structures of these $\mathrm{AlPO}_{4}$-based molecular sieves are three-

\footnotetext{
* Corresponding author.
}

dimensional networks in which alternating $\mathrm{AlO}_{4}$ and $\mathrm{PO}_{4}$ tetrahedra are interconnected via oxygen atoms. Basically, the frameworks of aluminophosphate molecular sieves are electro-neutral and the compounds have no ion-exchange capacity. In the context of catalysis, negative charges have been introduced into the network by replacing a portion of phosphorus or aluminum in the framework by silicon or other cations of lower oxidation states [3-5]. As a result, the positive counter-ions present in the extra-framework which balance the charges can provide acid-base functions. On the other hand, the incorporation of transition metal ele- 
ments into the framework of aluminophosphates will create sites for redox reaction. However, redox metal-substituted aluminophosphates have not yet found wide application as oxidation catalysts $[6,7]$.

The pinacol rearrangement is a valuable process for preparing aldehydes or ketones through the elimination of water and skeletal rearrangement of 1,2-diols. The reaction is usually carried out in the presence of an inorganic strong acid such as $\mathrm{H}_{2} \mathrm{SO}_{4}$ or $\mathrm{HClO}_{4}$, and at least an equimolar amount of the acid is required [8,9]. Relatively little work has been reported using a catalytic amount of strong acid $[10,11]$. The trend to replace the corrosive inorganic acids by solid catalysts has led to several reports applying solid acid catalysts in this reaction during the past two decades [1217]. Among them, zeolites including ZSM-5 [14]. $X$ and $Y[13-16]$ were the center of the studies. The faujasite group, especially HY and LaHY, of relatively large pore diameters was reported to give better activities, but also gave higher coking rates. In recent years, SAPO molecular sieves, which are considered to have weak acidity compared with zeolites, were also examined as catalysts for pinacol rearrangement [17]. The catalytic activity was found to be constrained by pore diameter, and SAPO- 37 and -5, both of larger pore diameters, gave higher activities than SAPO-11 and -34 . In the above-mentioned catalytic studies, pure diols were used as reactants and the reaction temperature was mostly in the range of $393-623 \mathrm{~K}$.

The catalytic properties of hetero-element-substituted aluminophosphate molecular sieves have been studied previously [18-21]. However, to the best of our knowledge, none of them has compared the relative hydrophilicity between APO molecular sieves and silica zeolites. Our previous study on the catalytic behaviors of Ti-substituted SAPO molecular sieves showed that the surface of APO molecular sieves was more hydrophilic than zeolites and in favor of the catalytic reactions involving polar reactants and non-polar products [22]. As the pinacol rearrangement reaction is akin to this category, the aim of the present investigation is to study the pinacol rearrangement over a series of MAPO molecular sieves in the presence of solvents and to compare their activities with those of zeolites. The reaction temperature $(383 \mathrm{~K})$ was kept lower than that reported in the literature. Various reaction factors were examined, including the kind of hetero-element substituted into the catalysts, the metal loading, different crystalline structures of the aluminophosphate molecular sieves, and solvents of different polarity.

\section{Experimental}

\subsection{Catalyst synthesis}

Aluminophosphate molecular sieves of AFI, AEL and VFI crystal structures incorporated with different hetero-elements were prepared by hydrothermal synthesis. Triethylamine (TEA) was used as template for MeAPO-5, and dipropylamine (DPA) for MeAPO-11 and MeVPI-5. The gel mixtures with the molar compositions 1.05TEA (DPA): $a \mathrm{MOx}: \mathrm{Al}_{2} \mathrm{O}_{3}: \mathrm{P}_{2} \mathrm{O}_{5}: 40 \mathrm{H}_{2} \mathrm{O} \quad(a=0.02,0.04$ and 0.08 ) were crystallized at $473 \mathrm{~K}$ for $48 \mathrm{~h}$ to synthesize MeAPO-5 and MeAPO-11, and at $418 \mathrm{~K}$ for $24 \mathrm{~h}$ to synthesize MeVPI-5. The starting materials for MOx were nitrate salts of $\mathrm{Cr}$ (III), $\mathrm{Mn}(\mathrm{II}), \mathrm{Fe}$ (III), Co(II), Ni(II), and Cu(II). Sodium silicate was used as the silicon source, $\mathrm{NH}_{4} \mathrm{VO}_{3}$ was the vanadium source, $\mathrm{ZnCl}_{2}$ was the zinc source, and $\mathrm{Ti}\left(\mathrm{O}^{\mathrm{i}} \mathrm{Pr}\right)_{4}$ was the titanium source. The solid products were filtered and washed thoroughly with deionized water. After calcination at $823 \mathrm{~K}$ for $8 \mathrm{~h}$ for MeAPO-5 and at $773 \mathrm{~K}$ for $24 \mathrm{~h}$ for MeAPO-11, the powder samples were ionexchanged with $1 \mathrm{~N} \mathrm{NH}_{4} \mathrm{Cl}$ solution, followed by calcination at $573 \mathrm{~K}$. MeAPO-8 catalysts were obtained by calcination of MeVPI-5 powders at $523 \mathrm{~K}$ for $8 \mathrm{~h}$.

\subsection{Characterization}

Powder X-ray diffraction patterns were obtained with a Scintag X1 automated powder diffractometer using $\mathrm{Cu} \mathrm{K} \alpha$ radiation. The refinement of lattice parameters was carried out using a step scan with $0.01^{\circ}$ and $3 \mathrm{~s}$ per step for data collection, followed by analysis with software using a peak finder program and lattice refinement function. BET surface area measurements were done volumetrically. The elemental contents in bulk were 
determined by ICP-MS (ELAN 5000) on the HCldissolved samples. The EDAX microanalysis with a scanning electron microscope (SEM) on the powder samples was performed with an Hitachi S-2400 instrument. The average of the data taken from three different points was used for quantitative comparison. The temperature-programmed desorption (TPD) experiments were carried out on a Du Pont 951 TGA analyzer. The solid state ${ }^{27} \mathrm{Al}$ MAS NMR spectra were obtained with a Chemagnetics CMX Infinity-600 spectrometer.

\subsection{Catalytic reaction}

The catalytic studies of the pinacol rearrangement reaction were carried out in a three-necked round-bottom flask fitted with a thermometer and a reflux condenser. A solution of pinacol $(1.0 \mathrm{~g})$ in organic solvent, where the molar ratio of solvent to pinacol was kept at 5 , was added into the flask containing $0.2 \mathrm{~g}$ of catalyst powders and a stir bar. The mixture was then stirred at $383 \mathrm{~K}$. Solvents of different polarity were used, including toluene, 2-octanone, benzonitrile and 1-butanol. The liquid products obtained after $3 \mathrm{~h}$ reaction were separated with a DP-1 capillary column and analyzed with an FID detector in a Chrompack CP9000 GC.

\section{Results and discussion}

\subsection{Catalyst characterization}

The incorporation of first row transition metal elements into the synthesis gel of aluminophosphate has different effects on the structure and morphology of the resultant products for different crystal systems. Table 1 summarizes the crystalline phases observed in the AFI and VFI systems. For the AFI system, pure crystalline phase is easy to obtain when the $\mathrm{M} / \mathrm{P}$ ratio of hetero-elements incorporated is less than 0.04 . In contrast, the products obtained from the VFI batches were frequently accompanied by an AEL structure. The single phase of the VFI structure was more easy to obtain when trivalent metal ions, such as $\mathrm{Cr}^{3+}$ and $\mathrm{Fe}^{3+}$, were introduced into the synthesis gels instead of divalent metal ions. The results of BET surface area measurement showed that larger surface areas were obtained when pure AFI and VFI crystalline structures were formed (Table 1). The situation became even more complicated in the synthesis of AEL crystals. Many impurity phases, including H3, MAPO-31, MAPO-41 and MAPO-46, and about eight different morphologies, were observed when hetero-elements were incorporated into the synthesis gels. Since it was difficult to obtain a pure crystalline phase of AEL structure, the study hereafter focuses mainly on the AFI and VFI systems.

The elemental analysis results are tabulated in Table 2 . Generally speaking, the metal contents in the crystals, based on the $\mathrm{M} / \mathrm{Al}$ molar ratios, are proportional to, but lower than, those added into the gels. As the metal content increases, the difference between the amount added in the gel and that incorporated into the crystals increases. These results suggest that there are limitations in the amount of hetero-elements that can be incorporated into the crystals. The other important point shown in Table 2 is that the Al/P molar ratios analyzed by ICP-MS are less than 1.0 for all the MeAPO samples, except Ti-SAPO-5 and VAPO-5 of high $\mathrm{V}^{5+}$ content. This implies that most of the metal ions probably substitute the Al tetrahedral sites on the framework.

In order to know the distribution of heteroelements in the crystals and infer the growing process of crystals, the crystal morphology was examined by SEM (Fig. 1) and the quantitative analysis data obtained by EDAX were compared with those from ICP-MS analysis (Table 2). In general, the appearance of MeAPO-5 crystals is dissimilar to those of $\mathrm{AlPO}_{4}-5$. The former is mainly global shapes and the latter is hexagonal pillar crystals. However, in detail, the global crystals of MeAPO-5 are gatherings of small hexagonal pillars (Fig. 1(A)). Hence, the main difference between MeAPO-5 and $\mathrm{AlPO}_{4}-5$ was the size of the hexagonal pillar crystals and how they gathered to form global particles. On the other hand, for the VFI structure, the addition of hetero-element metal ions during the synthesis process led to apparent changes in morphology (Fig. 1(B)). Instead of the smooth pillar crystals observed on VPI-5, the appearance of MeVPI-5 crystals turned 
Table 1

The crystal structures and surface areas of metal-substituted $\mathrm{AlPO}_{4}-5$ and VPI-5

\begin{tabular}{|c|c|c|c|c|}
\hline \multirow{2}{*}{$\begin{array}{l}\text { Metal ion } \\
\text { (M/Al molar ratio) }\end{array}$} & \multicolumn{2}{|l|}{$\mathrm{AlPO}_{4}-5$} & \multicolumn{2}{|l|}{ VPI-5 } \\
\hline & Crystal structure & Surface area $\left(\mathrm{m}^{2} \mathrm{~g}^{-1}\right)$ & Crystal structure & Surface area $\left(\mathrm{m}^{2} \mathrm{~g}^{-1}\right)$ \\
\hline$V^{5+}(2 \%)$ & AFI & 260 & $\mathrm{VFI}+\mathrm{s}^{\mathrm{b}} \mathrm{AEL}$ & 230 \\
\hline $\mathrm{Cr}^{3+}(2 \%)$ & AFI & 290 & VFI & 310 \\
\hline $\mathrm{Mn}^{2+}(2 \%)$ & $\mathrm{AFI}$ & 260 & $s \mathrm{AEL}+\mathrm{amo}$ & 200 \\
\hline $\mathrm{Fe}^{3+}(2 \%)$ & AFI & 290 & VFI & 300 \\
\hline $\mathrm{Co}^{2+}(2 \%)$ & $\mathrm{AFI}$ & 310 & VFI & 290 \\
\hline $\mathrm{Ni}^{2+}(2 \%)$ & $\mathrm{AFI}$ & 280 & $s \mathrm{VFI}+\mathrm{s} \mathrm{AEL}$ & 240 \\
\hline $\mathrm{Cu}^{2+}(2 \%)$ & AFI & 290 & $s \mathrm{VFI}+\mathrm{SAEL}$ & 190 \\
\hline $\mathrm{Zn}^{2+}(2 \%)$ & $\mathrm{AFI}+\mathrm{amo}^{\mathrm{a}}$ & 80 & --- & - \\
\hline$v^{5+}(1 \%)$ & AFI & 260 & $\mathrm{VFI}+\mathrm{s} A \mathrm{AEL}$ & 260 \\
\hline $\mathrm{V}^{5+}(4 \%)$ & AFI & 240 & $\mathrm{~s} \mathrm{VFI}+\mathrm{s} \mathrm{AEL}$ & 240 \\
\hline $\mathrm{Cr}^{3+}(1 \%)$ & $\mathrm{AFI}$ & 280 & VFI & 300 \\
\hline $\mathrm{Cr}^{3+}(4 \%)$ & AFI & 300 & $\mathrm{VFI}+?^{c}$ & 280 \\
\hline $\mathrm{Fe}^{3+}(1 \%)$ & AFI & 290 & VFI & 290 \\
\hline $\mathrm{Fe}^{3+}(4 \%)$ & $\mathrm{AFI}$ & 280 & VFI + s AEL & 220 \\
\hline
\end{tabular}

a Amorphous phase.

'Small amount.

'Unknown phase.

to rough surfaces with branches. As the content of metal ions increased, the surface of the pillar crystals grafted many small particles and crystallites. From the elemental analysis data shown in Table 2, the metal contents in the bulk of as-synthesized MeAPO crystals were apparently less than those on the superficial layers. This strongly suggests that the hetero-elements are not dispersed homogeneously throughout the crystals. From a combination of the SEM and EDAX results, the formation process of MeAPO crystals is proposed. In the initial stage of crystallization by hydrothermal methods, the aluminophosphate framework with low content of hetero-elements forms first. This serves as a seed for crystal growth. As the crystals grow larger, the metal-ion concentration in the gels increases gradually. This increase leads to a higher content of metal ions to be incorporated into the crystals. During this stage, a large quantity of defects is also formed and these defects prevent the approaching species from arranging in order. For MeVPI-5, these defects may act as the seeds for the growth of the smaller crystallites grafted on the large crystal surfaces. As for MeAPO-5, similar defects probably cause the formation of small crystals and their segregation into the spherical globes. However, these speculations will be continued further through more precise experiments, e.g. time-resolved analysis of the growing crystals.

The acidity of SAPO-5 and MeAPO-5 samples was examined by TPD of pyridine. Fig. 2 shows that pyridine was desorbed at relatively low temperatures and the desorption peaks appeared at $423-453 \mathrm{~K}$ for all the samples. Hence, all the SAPO-5 and MeAPO-5 samples are considered to have low acidity. As the desorption curves of Si-, $\mathrm{Ti} / \mathrm{Si}$-, and Fe-substituted AFI crystals extend to higher temperature relative to the other curves, the acid strength of these three samples is slightly stronger than the rest. In contrast, VAPO- 5 has one of the weakest acidities.

\subsection{Catalytic activity}

Table 3 compares the catalytic activities of different metal-containing AFI aluminophosphates with those of HZSM-5 and HY zeolites in pinacol rearrangement. The conversion of pinacol and the selectivity of pinacolone depend strongly on the 
Table 2

The elemental analysis results of synthesized MAPOs

\begin{tabular}{|c|c|c|c|c|c|c|c|}
\hline \multirow[t]{3}{*}{ Catalyst } & \multicolumn{7}{|c|}{ Molar ratio } \\
\hline & \multicolumn{3}{|l|}{ Gel } & \multicolumn{4}{|c|}{ Product } \\
\hline & $\mathbf{M}$ & $\mathrm{P}$ & $\mathrm{A} 1$ & $M^{a}$ & $\mathrm{~Pa}^{\mathrm{a}}$ & $\mathbf{A l}^{\mathrm{a}}$ & $M|A|^{b}$ \\
\hline $2 \%$ Ti-SAPO-5 & 0.02 & 1.0 & 1.0 & 0.019 & 0.94 & 1.00 & 0.04 \\
\hline $1 \%$ VAPO- 5 & 0.01 & 1.0 & 1.0 & 0.008 & 1.02 & 1.0 & $\ldots$ \\
\hline $2 \%$ VAPO- 5 & 0.02 & 1.0 & 1.0 & 0.014 & 1.01 & 1.0 & $\ldots$ \\
\hline $4 \%$ VAPO- 5 & 0.04 & 1.0 & 1.0 & 0.028 & 0.99 & 1.0 & -- \\
\hline $6 \%$ VAPO- 5 & 0.06 & 1.0 & 1.0 & 0.037 & 0.96 & 1.0 & $-\cdots$ \\
\hline $1 \%$ Cr-APO-5 & 0.01 & 1.0 & 1.0 & 0.008 & 1.03 & 1.0 & $\ldots$ \\
\hline $2 \% \mathrm{Cr}-\mathrm{APO}-5$ & 0.02 & 1.0 & 1.0 & 0.015 & 1.05 & 1.0 & 0.03 \\
\hline $4 \%$ Cr-APO-5 & 0.04 & 1.0 & 1.0 & 0.021 & 1.05 & 1.0 & - \\
\hline $2 \% \mathrm{Mn}-\mathrm{APO}-5$ & 0.02 & 1.0 & 1.0 & 0.017 & 1.06 & 1.0 & - \\
\hline $1 \% \mathrm{Fe}-\mathrm{APO}-5$ & 0.01 & 1.0 & 1.0 & 0.008 & 1.03 & 1.0 &.-- \\
\hline $2 \% \mathrm{Fe}-\mathrm{APO}-5$ & 0.02 & 1.0 & 1.0 & 0.019 & 1.04 & 1.0 & 0.07 \\
\hline $4 \% \mathrm{Fe}-\mathrm{APO}-5$ & 0.04 & 1.0 & 1.0 & 0.031 & 1.07 & 1.0 & - \\
\hline $2 \%$ CO-APO-5 & 0.02 & 1.0 & 1.0 & 0.018 & 1.03 & 1.0 & 0.05 \\
\hline $2 \% \mathrm{Ni}-\mathrm{APO}-5$ & 0.02 & 1.0 & 1.0 & 0.017 & 1.01 & 1.0 & $\ldots \ldots$ \\
\hline $2 \% \mathrm{Cu}-\mathrm{APO}-5$ & 0.02 & 1.0 & 1.0 & 0.007 & 1.01 & 1.0 & 0.05 \\
\hline $2 \% \mathrm{Zn}-\mathrm{APO}-5$ & 0,02 & 1.0 & 1.0 & 0.012 & 1.08 & 1.0 & $\ldots$ \\
\hline Imp. $2 \%$ Fe-APO- 5 & 0.02 & 1.0 & 1.0 & 0.016 & 1.01 & 1.0 & 0.03 \\
\hline $2 \% \mathrm{Fe}-\mathrm{APO}-11$ & 0.02 & 1.0 & 1.0 & 0.018 & 1.03 & 1.0 & 0.04 \\
\hline $2 \% \mathrm{Fe}-\mathrm{VPI}-5$ & 0.02 & 1.0 & 1.0 & 0.015 & 1.01 & 1.0 & 0.05 \\
\hline $2 \%$ V-VPI-5 & 0.02 & 1.0 & 1.0 & 0.013 & 1.01 & 1.0 & 0.06 \\
\hline
\end{tabular}

${ }^{\mathrm{a}}$ From ICP-MS elemental analysis; data deviation for $\mathrm{M}= \pm 0.01$.

${ }^{b}$ From EDAX analysis; data deviation \pm 0.01 .

kinds of metal ion incorporated in AFI. Among $\mathrm{Si}$ and the first row transition metal elements, $\mathrm{Fe}^{3+}, \mathrm{Cu}^{2+}$ and $\mathrm{Ni}^{2+}$ in order are the three which give the highest activities. Also, the pinacolone selectivities for these three catalysts are over $80 \%$. The variation in catalytic activities, however, has no direct correlation with the acidity of the catalysts measured by TPD of pyridine. In addition, under the same reaction condition, HY and HZSM-5 zeolites of relatively strong acidity, have low catalytic activities. These results can only be explained by the fact that the acidity of these heterogeneous catalysts is not the main factor in catalyzing the pinacol rearrangement. Moreover, since the pinacolone selectivities are lower over the silica zeolites than over aluminophosphates, the surface polarity of the catalysts may also affect the catalytic activity.

The influence of metal content and variation in aluminophosphate crystal structure is also shown in Table 3. There is no direct correlation between the pinacol conversion and the metal content in the catalysts. However, the selectivity of pinacolone seems to decrease as the metal content increases. That is more clearly shown in the molar ratio of the two main products, pinacolone $(P)$ and 2,3-dimethyl-1,3-butadiene (D). The P/D molar ratios decrease from $5.9,4.7$ to 4.2 over FeAPO-5, and from 5.7, 5.1 to 1.8 over VAPO-5 when the metal content increases from 1,2 to $4 \%$. The reaction path of pinacol rearrangement was examined by plotting the yields and selectivities of these two main products versus pinacol conversion (Fig. 3). Since there was no inter-conversion between these two products, they were concluded to form through parallel paths. The effect of metal content, therefore, implies that diene is probably formed on the catalyst surfaces where several metal centers aggregate or more defects are present, whereas pinacolone is probably formed on isolated 

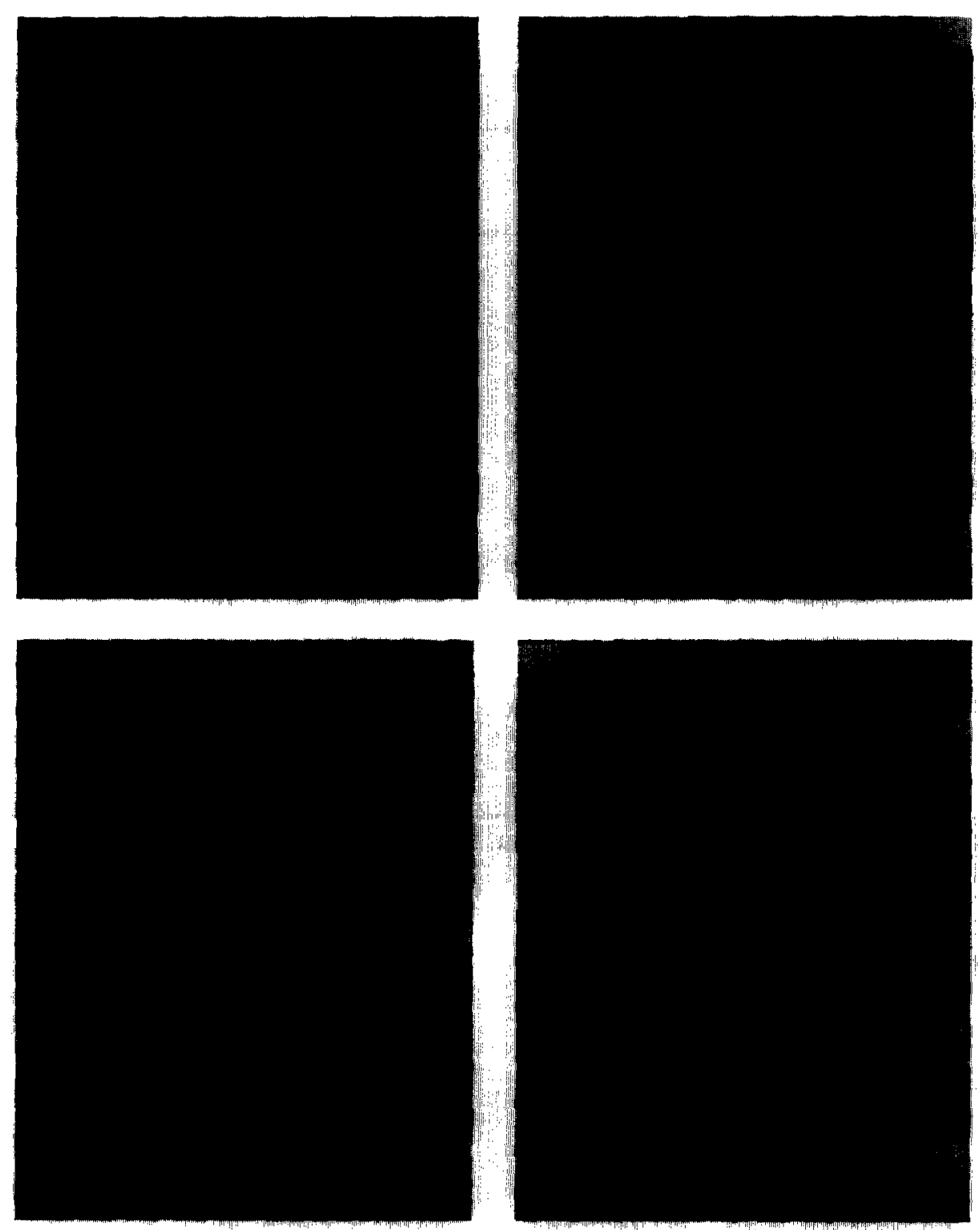

Fig. 1. SEM photographs of (A) AFI crystals: (a) pure $\mathrm{AlPO}_{4}-5$, (b) $1 \%$ Fe-, (c) $2 \%$ Fe- and (d) $4 \%$ Fe-substituted samples; (B) VFI crystals: (a) pure VPI-5, (b) $1 \% \mathrm{Cr}-$, (c) $2 \% \mathrm{Cr}$ - and (d) $4 \% \mathrm{Cr}$-substituted samples.

metal centers. In addition, an impregnated $2 \%$ $\mathrm{Fe}$-containing $\mathrm{AlPO}_{4}-5$ was prepared to compare its catalytic activity with that prepared by hydrothermal synthesis. Over the impregnated catalyst, the pinacol conversion is much lower and the diene selectivity is slightly higher. This result confirms that the active sites for the high activities observed on the Fe-substituted APO-5 catalysts cannot be the small clusters of iron oxide.

A comparison of the $2 \% \mathrm{Fe}^{3+}$-incorporated molecular sieves of different crystal structures in Table 3 shows that the catalytic activity decreases in the order of APO-5>APO-11 $\geq$ APO-8 $>$ VPI-5> silicalite-1. In agreement with the catalytic 

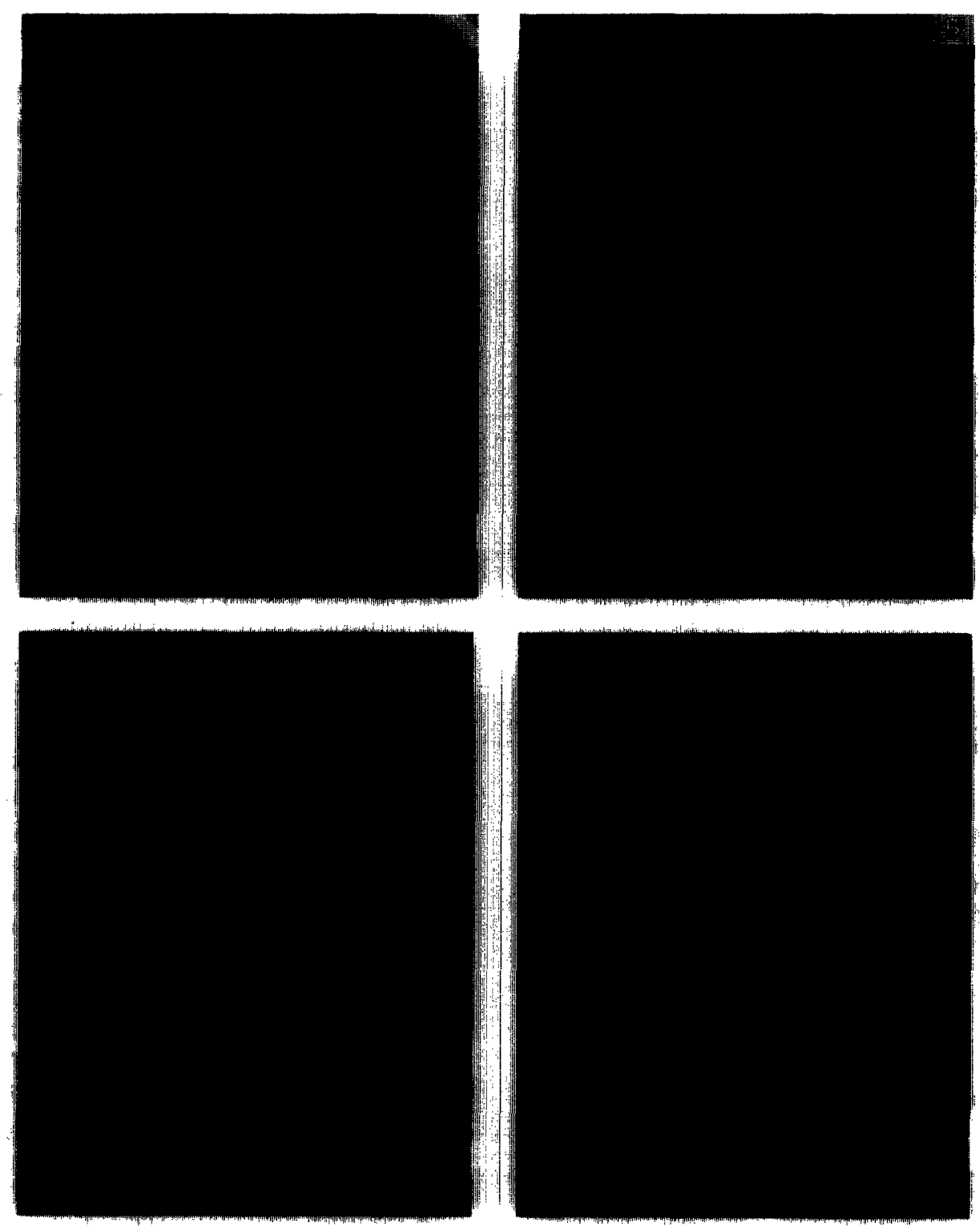

Fig. 1. (continued)

performance of HZSM-5 and $\mathrm{HY}, \mathrm{Fe}^{3+}$ substituted silicalite- 1 shows the lowest activity in the pinacol rearrangement reaction. This is attributed to the relatively low adsorption capability of the hydrophobic surfaces of silica zeolites towards the diol reactants. On the other hand, the catalytic activity was not dependent on the pore diameter of the molecular sieve catalysts. This implies that these liquid-phase reactions probably proceed mainly on the surfaces outside the channels of the molecular sieves. As to how the different crystal structures of the aluminophosphates affect the catalytic activity, the explanation probably lies in the local coordination environment of metal centers on the outer surfaces.

The solvent used in the reaction was found to affect both the pinacol conversion and pinacolone selectivity (Table 4). Four solvents were used, 


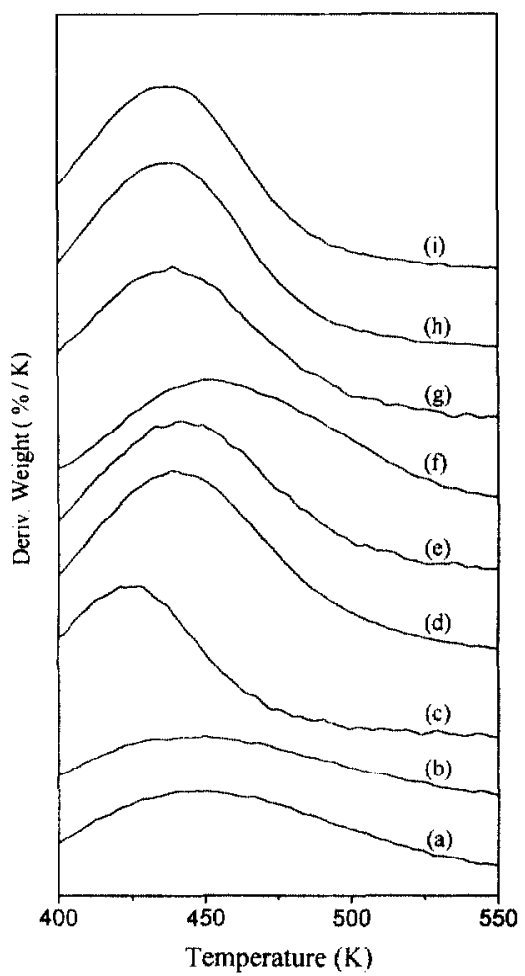

Fig. 2. The TPD profiles of pyridine over: (a) SAPO-5; (b) $2 \%$ Ti-SAPO-5; (c) $2 \%$ VAPO- 5 ; (d) $2 \%$ CrAPO-5; (e) $2 \%$ MnAPO-5; (f) $2 \%$ FeAPO-5; (g) $2 \%$ CoAPO-5; (h) $2 \%$ NiAPO-5; (i) $2 \%$ CuAPO-5.
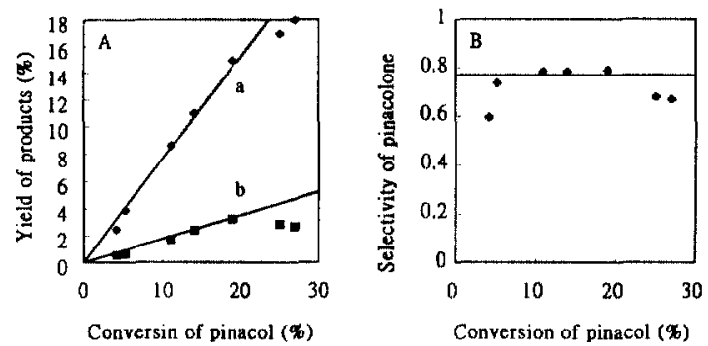

Fig. 3. Variation of (A) the yields of pinacolone ( ) and DMBDE $(\boldsymbol{a})$, and $(\mathbf{B})$ the selectivity of pinacolone versus conversion of pinacol.

and their polarity increases in the order of toluene $<2$-octanone $<$ benzonitrile $<$ butanol. The pinacol conversions over MeAPO-5 using 2octanone and toluene as solvents were high, whereas the conversion decreased markedly when the more polar solvents, benzonitrile and butanol, were used. These results are attributed to the fact that the polar solvent molecules will compete for adsorption on the hydrophilic surfaces of aluminophosphates and, therefore, impede the approach of diol reactants to the active sites. On comparing the results of using toluene and 2-octanone as solvents, the latter tends to give a higher conversion than the former. In addition, although the pinacolone selectivities obtained from these two solvents are of a similar range, the molar ratios of the two main products are very different. This suggests that the solvent tends to induce products of similar functionality even in the heterogeneous catalytic system. The reason for this phenomenon is probably due to the fact that the solvent plays an important role in carrying the product molecules away from the surface of the catalyst. As soon as the product molecules are carried away the active sites are then available for the incoming reactants. Therefore, the interactions between the catalyst surface and the reactant, the surface and solvent, as well as the product and solvent, are important factors which influence the results of heterogeneous catalytic reactions in liquid solutions.

The metal ions incorporated in the aluminophosphate framework will play an important role in the catalytic process. $\mathrm{Fe}^{3+}$-substituted aluminophosphate molecular sieves were first synthesized by researchers at Union Carbide [23]. $\mathrm{Fe}^{3+}$ was considered to substitute the tetrahedral sites of $\mathrm{Al}^{3+}$ in the framework. Unlike SAPOs or the divalent-metal-substituted MeAPOs, FeAPOs were considered to contain no charge in the framework. Hence, although FeAPOs have been investigated as catalysts in several reactions $[24,25]$, the catalytic activities were not related to the presence of acid sites in the framework. The calcined AFI and the as-synthesized VFI aluminophosphates were highly hydrophilic. Solid state ${ }^{27}$ Al MAS NMR spectra showed that a portion of the $\mathrm{Al}^{3+}$ ions in the framework was octahedrally coordinated. After degassing the samples at ambient temperatures for 2 days, all the octahedral sites converted to tetrahedral sites. The transformation was found to be reversible, and the octahedral signal could be regained by exposing the degassed samples in air. These results imply that the nature of the 
Table 3

The influence of metals substitution, metal content and different crystalline structures of molecular sieves in pinacol rrearrangement

\begin{tabular}{|c|c|c|c|c|c|}
\hline \multirow[t]{2}{*}{ Catalyst } & \multirow[t]{2}{*}{$E_{\mathrm{red}}^{0}(\mathrm{~V})$} & \multirow[t]{2}{*}{ Pinacol conversion $(\%)$} & \multicolumn{2}{|c|}{ Selectivity $(\%)$} & \multirow[t]{2}{*}{$\mathrm{P} / \mathrm{D}$ ratio } \\
\hline & & & Pinacolone & DMBDE & \\
\hline HZSM-5 & $\ldots$ & 4.1 & 54 & 12 & 4.4 \\
\hline $\mathrm{HY}$ & $\ldots$ & 5.2 & 35 & 17 & 2.1 \\
\hline $\mathrm{AlPO}_{4-5}-5$ & - & 4.6 & 67 & 15 & 4.8 \\
\hline $2 \%$ SAPO-5 & $-\ldots$ & 3.2 & 75 & 19 & 3.8 \\
\hline $2 \%$ Ti- SAPO- 5 & - & 1.8 & 67 & $\ldots$ & $-\ldots$ \\
\hline $2 \% \mathrm{~V} \cdot \mathrm{APO}-5$ & +1.00 & 3.4 & 65 & 12 & 5.1 \\
\hline $2 \% \mathrm{Cr}-\mathrm{APO}-5$ & -0.41 & 6.3 & 65 & 19 & 3.4 \\
\hline \multirow{2}{*}{$2 \%$ Mn-APO- 5} & & 9.4 & 67 & 18 & 3.8 \\
\hline & $\begin{array}{l}+1.23\left(\mathrm{Mn}^{4+}\right) \\
-1.18\left(\mathrm{Mn}^{2+}\right)\end{array}$ & & & & \\
\hline $2 \% \mathrm{Fe}-\mathrm{APO}-5$ & +0.77 & 69 & 81 & 17 & 4.7 \\
\hline \multirow[t]{2}{*}{$2 \% \mathrm{Co}-\mathrm{APO}-5$} & & 14 & 67 & 17 & 3.7 \\
\hline & $\begin{array}{l}+1.84\left(\mathrm{Co}^{3+}\right) \\
-0.28\left(\mathrm{Co}^{2+}\right)\end{array}$ & & & & \\
\hline $2 \% \mathrm{Ni}-\mathrm{APO}-5$ & -0.28 & 50 & 80 & 17 & 4.8 \\
\hline $2 \%$ Cu-APO-5 & +0.15 & 54 & 80 & 14 & 5.8 \\
\hline $2 \% \mathrm{Zn}-\mathrm{APO}-5$ & -0.76 & 28 & 75 & 16 & 4.6 \\
\hline $1 \% \mathrm{Fe}-\mathrm{APO}-5$ & & 51 & 84 & 14 & 5.9 \\
\hline $4 \% \mathrm{Fe}-\mathrm{APO}-5$ & & 60 & 80 & 18 & 4.2 \\
\hline $1 \%$ V APO-5 & & 11 & 63 & 11 & 5.7 \\
\hline $4 \%$ V-APO-5 & & 2.9 & 55 & 31 & 1.8 \\
\hline Imp. $2 \% \mathrm{Fe}-\mathrm{APO}-5$ & & 10 & 81 & 20 & 4.0 \\
\hline $2 \% \mathrm{Fe}-\mathrm{VPI}-5$ & & 8.4 & 75 & 20 & 3.8 \\
\hline $2 \% \mathrm{Fe}-\mathrm{VPI}-8$ & & 30 & 70 & 18 & 3.8 \\
\hline $2 \%$ Fe-APO- 11 & & 32 & 62 & 19 & 3.2 \\
\hline $2 \%$ Fe-silacalite- 1 & & 3.6 & 50 & 31 & 1.6 \\
\hline
\end{tabular}

Al--O bonds are more ionic than covalent and that the framework is flexible enough to accommodate the change in coordination of $\mathrm{Al}^{3+}$ easily.

It is reasonable to believe that similar changes in coordination environment around the heteroelements can be achieved when they are incorporated on the aluminophosphate framework. The metal centers which can reversibly adsorb water molecules will be the active site for catalytic reactions. Accordingly, the reaction mechanism of pinacol rearrangement over FeAPO-5 shown in Scheme. 1 is proposed. On the hydrophilic surface of $\mathrm{Fe}^{3+}$-substituted aluminophosphates, the coordination sites where $\mathrm{H}_{2} \mathrm{O}$ molecules reversibly adsorb are replaced by the pinacol molecule. The proton on the $\mathrm{OH}$ group which coordinates to

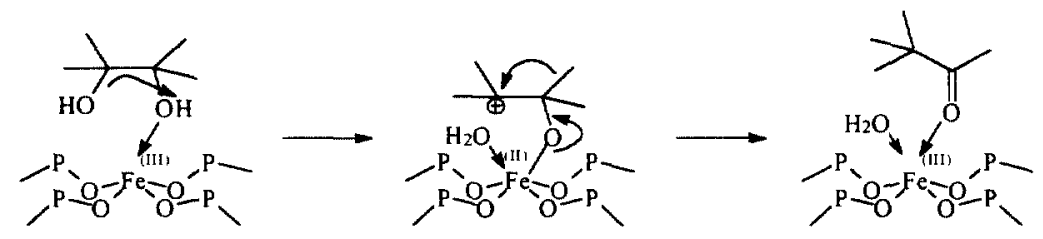

Scheme 1. Proposed reaction path of pinacol rearrangement over FeAPO. 
Table 4

The solvent effect in pinacol rearrangement catalyzed by Me-APO-5

\begin{tabular}{|c|c|c|c|c|c|}
\hline \multirow[t]{2}{*}{ Solvent } & \multirow[t]{2}{*}{$\mathrm{Me}$} & \multirow[t]{2}{*}{ Pinacol conversion $(\%)$} & \multicolumn{2}{|c|}{ Selectivity $(\%)$} & \multirow[t]{2}{*}{ F/D ratio } \\
\hline & & & Pinacolone & DMBDE & \\
\hline \multirow[t]{3}{*}{ Toluene } & $\mathrm{Fe}^{3+}$ & 69 & 81 & 17 & 4.7 \\
\hline & $\mathrm{Ni}^{2+}$ & 50 & 80 & 17 & 4.8 \\
\hline & $\mathrm{Cu}^{2+}$ & 54 & 80 & 14 & 5.8 \\
\hline \multirow[t]{3}{*}{ 2-Octanone } & $\mathrm{Fe}^{3+}$ & 87 & 79 & 5.0 & 16 \\
\hline & $\mathrm{Ni}^{2+}$ & 83 & 75 & 4.9 & 15 \\
\hline & $\mathrm{Cu}^{2+}$ & 85 & 79 & 8.6 & 9.1 \\
\hline \multirow[t]{3}{*}{ Benzonitrile } & $\mathrm{Fe}^{3+}$ & 7.3 & 58 & 15 & 3.8 \\
\hline & $\mathrm{Ni}^{2}+$ & 6.4 & 55 & 14 & 3.9 \\
\hline & $\mathrm{Cu}^{2+}$ & 6.8 & 68 & 13 & 5.1 \\
\hline \multirow[t]{3}{*}{ Butanol } & $\mathrm{Fe}^{3+}$ & 3.2 & 88 & 0 & $\varkappa$ \\
\hline & $\mathrm{Ni}^{2+}$ & 2.2 & 86 & 0 & $c$ \\
\hline & $\mathrm{Cu}^{2+}$ & 2.9 & 90 & 6.7 & 13 \\
\hline
\end{tabular}

Reaction conditions: weight ratio of pinacolcalalyst $=5: 1,383 \mathrm{~K}: 3 \mathrm{l}$.

$\mathrm{Fe}^{3+}$ becomes so acidic that it transfers easily to the other $\mathrm{OH}$ group on the pinacol molecule. The formation of an $\mathrm{Fe}(\mathrm{II})-\mathrm{O}$ bond facilitates the dehydration of coordinated pinacol and stabilizes the carbenium ion intermediate. As the electron pair back-donates from the $\mathrm{O}-\mathrm{Fe}$ ( II) bond to the $\mathrm{C}-\mathrm{O}$ bond, the methyl group migrates to the cation site and $\mathrm{Fe}(\mathrm{II})$ is oxidized back to $\mathrm{Fe}$ (III). The pinacolone molecule formed is easily removed by the solvent and the coordination site around $\mathrm{Fe}(\mathrm{III})$ is replaced by another pinacol or water molecule.

The discrepancy in catalytic activities of different metal-substituted aluminophosphates is therefore attributed to the coordinative ability and the redox capability of the metal ion center. The standard reduction potentials of metal species incorporated in aluminophosphate are presented in Table 3. Metal centers of low redox capability, such as $\mathrm{Cr}^{3+}, \mathrm{Mn}^{2+}$ and $\mathrm{Zn}^{2+}$, cannot stabilize the carbenium ion intermediate. In contrast, metal centers of high oxidation capability, such as $\mathrm{V}^{5+}, \mathrm{Mn}^{4+}$ and $\mathrm{Co}^{3+}$, will tend to oxidize the reactant or intermediates to oxidized products. This proposal was affirmed by noticing that acetone was detected in the products over most of the catalysts which showed low activities. Since acetone is formed through an oxidation reaction, the metal centers must be reduced. As a result, metal ions of high oxidation capability gave low catalytic activities in this reaction.

\section{Acknowledgement}

Financial support from the National Sicience Council of Taiwan, R.O.C., is gratefully acknowledged. Thanks are also extended to Professor Gary E. Maciel and his research group at the Department of Chemistry, Colorado State University, for the technical assistance and valuable discussion on the solid state NMR experiments.

\section{References}

[1] S.T. Wilson, B.M. Lok, C.A. Messing, T.R. Cannan, E.M. Flanigen, J. Am. Chem. Soc. 104 (1982) 1146.

[2] S.T. Wilson, B.M. Lok, E.M. Flanigen, US Patent $4310440,1982$.

[3] B.M. Lok, C.A. Messina, R.L. Patton, R.T. Gajck, T.R. Cannon. E.M. Flanigen, US Patent $4440871,1984$.

[4] S.T. Wilson, E.M. Flanigen, European Patent 1.32708 , 1985.

[5] S.T. Wilson, E.M. Flanigen. US Patent 4567029.1986.

[6] J.-D. Chen, J. Dakka, E. Neeleman, R.A. Sheldon, J. Chem. Soc. Chem. Commun. (1993) 1379.

[7] S.J. Kulkarni, R.R. Rao. M. Subrahmanyam, S 
Farsinavis, P.K. Rao, A.V.R. Rao, Indian J. Chem. Soc A 35 (1996) 740 .

[8] C.A. Buehler, D.F. Pearson, Survey of Organic Synthesis Wiley-Interscience, New York, 1970, p. 677.

[9] P. de Mayo, Rearrangement in Ground and Excited States, vol. 1, Academic Press, New York, 1985.

[10] T. Mukaiyama, M. Katsurada, T. Takashima, Chem. Lett. (1991) 985 .

[11] T. Harada, T. Mukaiyama, Chem. Lett. (1992) 81.

[12] E. Gutierrez, A.J. Aznar, E. Ruiz-Hitzky, in: M. Guisnet et al. (Eds), Heterogeneous Catalysis and Fine Chemicals, Elsevier, Amsterdam, 1988, p. 211.

[13] A. Molnar, I. Bucsi, M. Bartok, in: M. Guisnct et al. (Eds), Heterogeneous Catalysis and Fine Chemicals, Elsevier, Amsterdam, 1988, p. 203.

[14] C.P. Bezouhanova, F.A. Jabur, J. Mol. Catal. 87 (1994) 39.

[15] W.F. Holderich, H. van Bekkum, in: H. van Bekkum, E.M. Flanigen, J.C. Jansen (Eds), Introduction to Zeolite Science and Practice, Studies in Surface Science and Catalysis. Vol. 58, Elsevier, Amsterdam, 1991, p. 654.
[16] A.P. Nefedova, Z.V. Gryaznova, G.V. Tsitsishwili, A.Yu Krupennikova, Neftekhimia 19 (1979) 113.

[17] F.A. Jabur, V.J. Penchev, C.P. Bezoukhanova, I. Chem Soc. Chem Commun. (1994) 1591.

[18] P. Concepcion, J.M. Lopez Nieto, A. Mifsud, J. PerezPariente, Appl. Catal. A 151 (1997) 373.

[19] F.J. Luna, S.E. Ukawa, M. Wallau, U. Schuchardt, J. Mol. Catal. 117 (1997) 405.

[20] A. Tuel, Zeolites 15 (1995) 228.

[21] P.S. Singh, R.A. Shaikh. R. Bandyopadhyay, B.S. Rao. J. Chem. Soc. Chem. Commun. (1995) 2255.

[22] B.-Y. Hsu, Ph.D. Dissertation, National Taiwan University, Taipej, Taiwan, 1997.

[23] C.A. Messina, B.M. Lok, E.M. Flanigen, European Patent $131946,1984$.

[24] A.F. Ojo, J. Dwyer, R.V. Parish, Stud. Surf. Sci. Catal. A 49 (1989) 227.

[25] P. Wenqin, Q. Shilun, K. Quibin, W. Zhiyun, P. Shaoyi, F. Guochuan, T. Di, Stud. Surf. Sci. Catal. A 49 (1989) 281 